\title{
Prevalence, Trends and Predictors of Small Size Babies in Nigeria: Analysis of Data from Two Recent Nigeria Demographic and Health Surveys
}

\author{
Anthony Ike Wegbom ${ }^{1,4,}$, Clement Kevin Edet ${ }^{2}$ and Victor Alangibi Kiri ${ }^{1,3}$ \\ ${ }^{1}$ Department of Mathematics, Rivers State University, Port Harcourt, Nigeria \\ ${ }^{2}$ Department of Planning, Research and Statistics, Rivers State Primary Health Care Management Board, \\ Port Harcourt, Nigeria \\ ${ }^{3}$ Department of Mathematics, Physics \& Electrical Engineering, Northumbria University, Newcastle Upon \\ Tyne, UK \\ ${ }^{4}$ Department of Statistics, Captain Elechi Amadi Polytechnic, Port Harcourt, Nigeria
}

\begin{abstract}
Background: Despite low birth weight (LBW) role on child growth, development, and survival in developing countries, it has not been given the desired priority in terms of research, at the national level in Nigeria. Our study aims to estimate the trend in the prevalence of small size babies and to identify its predictors using nationally representative data.

Methods: We used the 2013 and 2018 data from the Nigeria Demographic and Health Survey using the statistical methods of descriptive analysis and logistic regression modelling.

Results: The proportion of babies reported to have small size at birth in Nigeria declined from $14.9 \%$ in 2013 to $13.7 \%$ in 2018. Various factors from demographic, socio-economic, and health-seeking behaviour were identified as significant predictors. Women who received iron pills and tetanus toxoids during pregnancy had at most $79 \%$ and $80 \%$ less risk of having small size babies, respectively, than those who received none of these two. Female children had at least $21 \%$ more chance of being small in size than male children. Other key predictors were geopolitical region, maternal age at child birth, maternal literacy level, wealth status, religion, source of water supply, number of ANC visits during pregnancy, and desirousness of pregnancy.
\end{abstract}

Conclusion: In light of the adverse effects of low birth weight on child well-being, we recommend the implementation and prioritization of active, resourceful public health interventions that account for the findings of this study, if Nigeria is to sustain the progress achieved so far in reducing its current high rate.

Keywords: Prevalence, Trends, Risks factors, Small size baby, Low birth weight, Nigeria.

\section{INTRODUCTION}

Certain post maternal outcomes have long been identified as major public health problems. One of these is low birth weight (LBW). Birth weight is one of the significant predictors of child development, growth, as well as morbidity and mortality [1-3]. Low birth weight (LBW) is defined as a child weight less than $2500 \mathrm{~g}$ measured within 24 hours of birth [4]. The proportion of infants with low birth weight mirrors the socio-economic development of any region or country [2]. LBW is a major factor contributing to high infant mortality in developing countries, including Nigeria. Children born with LBW were estimated to have a higher risk of death before age five than children with normal birth weight (birth weight more than 2500g) [5-7]. There are little chances of reaching full growth potential for infants who manage to survive, in terms of

*Address correspondence to this author at the Department of Mathematics, Rivers State University, Port Harcourt, Nigeria; Tel: +1238032565971;

E-mail: wegbomanthony@gmail.com lower intelligent quotient (IQ), difficulties in school and brain retardation, stunting, heart disease, and diabetes in adulthood [8-10]. Globally, LBW contributes to between 40 to 60 percent of neonatal mortality [11].

Over 20.5 million babies were born with low birth weight in 2015 , constituting about $14.6 \%$ of all births worldwide- Asia accounted for half, while Africa contributed a quarter of all low birth weight babies in the world. East and West African countries had the highest LBW in Africa, implying that over $95 \%$ of them were in developing countries [10]. The prevalence of LBW varied across regions and countries. For instance, it ranged from $9 \%$ in Latin America, $13 \%$ in subSaharan Africa, to $28 \%$ in South Asia [12]. These disparities also subsisted in the 2015 LBW estimates, from $9.9 \%$ in Oceania to $13.7 \%$ in Africa and $17.3 \%$ in Asia. Because of the high prevalence of LBW across regions and countries, and its recognition as a public health priority, the World Health Assembly (WHA) member states endorsed a global reduction of low birth weight prevalence to $10.5 \%$ or less between 2012 and 2025 at their 65th meeting [10]. 
Nigeria recorded an LBW prevalence of about $17 \%$ between 2010 to 2015, which was considered one of the highest in sub-Saharan Africa [13]. According to the Multiple Indicator Cluster Survey (MICS) 2017 [14], the prevalence of LBW was $14.8 \%$; only about $37.5 \%$ were women delivered in a health facility, and skilled health workers assisted $43 \%$ of these. These estimates suggested $62.5 \%$ of the deliveries took place at home, from which $57 \%$ of these assisted by non-health workers, such as traditional birth attendants (TBA). Consequent upon this, it would have been challenging to have recorded babies' weight at-home delivery, as a result of nonexistence of weighing facilities and knowledge of its importance on child health. Hence, the sizes of babies at birth, as perceived by their mothers, were considered as acceptable alternatives to actual birth weights. This is the reality of the data available in national surveys such as the Demographic Health Survey (DHS) and MICS. There is a paucity of research on LBW at the national level in Nigeria, despite its importance as a significant predictor of infant mortality and as a public health problem. This gap may be attributed to the non-availability of appropriate data. This study aims to estimate the trend in the prevalence of small size babies and to identify its predictors using nationally representative data. Small size is used as a proxy of LBW. This is important as it will enable policymakers to design policies that can enhance child survival and increase the change of achieving the 2030 Sustainable Development Goals in Nigeria.

\section{METHODS}

\section{Data Source}

This study used data from the Nigeria Demographic and Health Survey (NDHS) conducted by the National Population Commission (NPC) and ICF international in 2013 and 2018. The survey is usually conducted every five years- each covering a 5 -year period that started in 1990 and involved women and men of reproductive age (i.e., women aged 15-49 and men aged 15-59), selected through a stratified two-stage cluster sampling technique.

\section{Study Variables}

The size of babies at birth, as perceived by the mothers of the babies born within the survey period was considered as the outcome variable, while the explanatory variables included demographic, socioeconomic, and healthcare-related behavioural factors.
The baby size at birth was obtained by asking the mother: whether the child was born very large, more than average, average, smaller than average, or very small. Demographic factors included sex of a child, region, place of residence, maternal age at child birth, the number of children ever born, and preceding birth interval. Socio-economic variables include maternal education, household wealth index, marital status, type of marriage, religion, and source of water. And the healthcare-related factors include the use of mosquito net, the number of antenatal care (ANC) attended, the use of iron tablets during pregnancy, and tetanus injection status during pregnancy.

\section{Data Analysis}

To create a binary outcome variable out of the data on baby size, we defined the combined categories of smaller than average and very small as small size, which we considered as a proxy to low birth weight (LBW). Thus, the prevalence of low birth weight was estimated based on the values: $L B W=1$ for small sized babies and $\mathrm{LBW}=0$ for greater than or equal to average-sized babies. As the first stage, the Chisquare test $(x 2)$ was performed to explore a possible relationship between low birth weight and each of the explanatory variables. Those with significant results were subsequently included in a multiple logistic regression analysis to assess the independent effect of each of these (i.e., having controlled for the impact of the other factors) [15]. For a variable to be considered as having an association with LBW, the 95\% confidence interval for the corresponding odds ratio (OR) must not include the value of 1 , which also meant a $p$-value $<0.05$. We used the STATA statistical package (version 15) for all analyses.

\section{RESULTS}

Figure 1 presents the distribution of babies by size at birth as perceived by their mothers from the 2013 and 2018 NDHS surveys that covered the 5-year periods 2009-2013 and 2014-2018, respectively. It shows a slight decline from 2009 to 2018 in the smaller than average size $(10.7 \%$ vs. $10.4 \%)$ and the very small sizes $(4.2 \%$ vs. $3.3 \%)$. But there was substantial decline in the other sizes- very large sizes $(13.5 \%$ vs $9.2 \%)$, large sizes (30.5\% vs $24.5 \%$ ) and average sizes $(41.1 \%$ vs $52.6 \%)$. Therefore, the prevalence of low birth weight (i.e. babies with smaller than average sizes and those with very small sizes) was $14.9 \%$ (i.e. $10.7 \%$ $+4.2 \%$ ) as at 2013 and $13.7 \%$ (i.e. $10.4 \%+3.3 \%$ ) as at 2018 . 


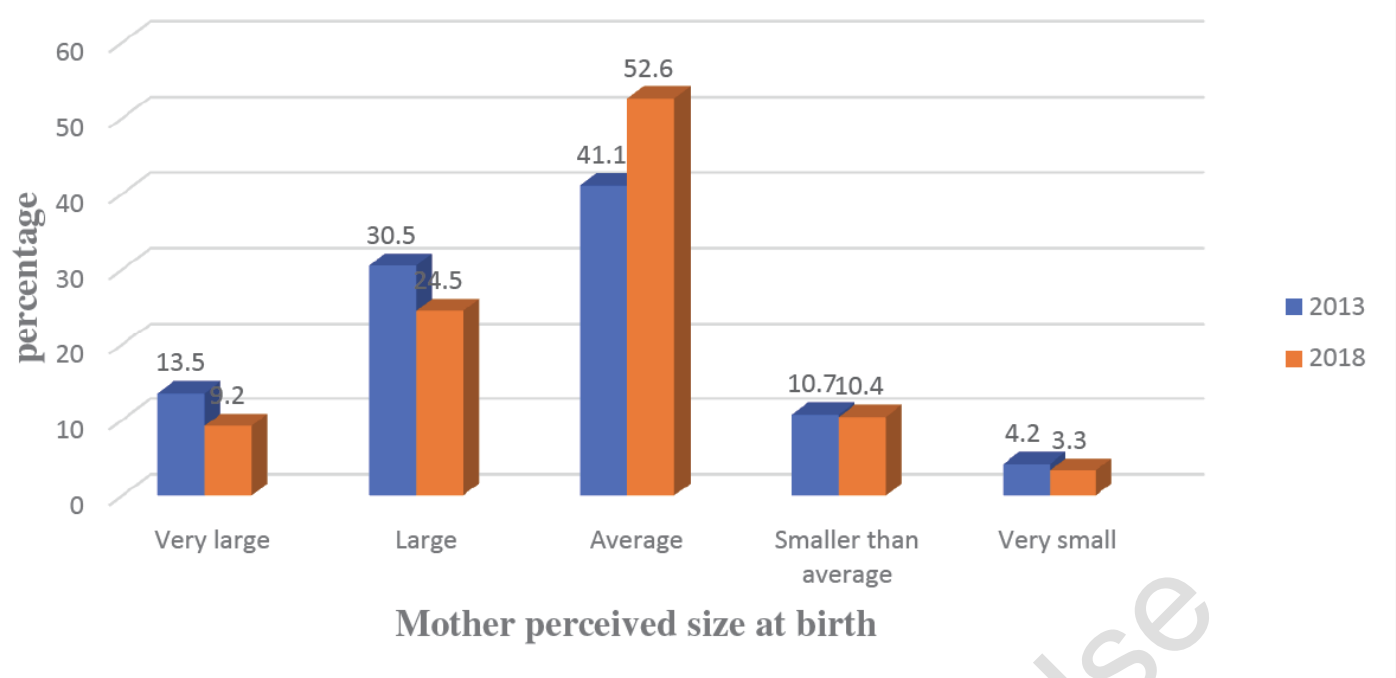

Figure 1: Trends in percentage distribution of mother perceived Infant Size at Birth, 2009-2018.

Table 1 presents the trends in the prevalence of small size babies and its prevalence across the study variables. The highest prevalence was observed in those residing in the rural areas compared with those in urban residence as at $2013(32.7 \%$ vs. $5.7 \%)$, and the difference was statistically significant, whereas there was no difference between those residing in rural and urban areas (14.2\% vs. $12.1 \%)$. We also observed a high prevalence of small size babies in the women that made between 1-3 ANC visits over the two survey periods: $21.4 \%$ for the $2009-2013$ period and $15.6 \%$ for the 2014-2018 period; while women who did not attend ANC had $19.4 \%$ in the first survey period and $16.3 \%$ in the second. There was no difference in prevalence between male and female babies in either the survey period.

As for the geopolitical region, we observed a high prevalence of small sized babies in the North compared with the South. In the two survey periods from 2009-2014 and 2015-2018, the North-East had the highest prevalence $(19.3 \%$ and $16.4 \%$ respectively), while the South-West had the lowest prevalence $(9.1 \%$ and $9.8 \%$ respectively). The NorthWest and North-Central both had a slight increase between the two periods from $16.8 \%-14.9 \%$ and $11.0 \%$ - $12.3 \%$ respectively; both the South-East $(12.3 \%$ and $11.1 \%)$ and South-South $(12.4 \%$ and $11.4 \%)$ regions had slight reductions between the two periods.

The results did not indicate a clear pattern on the prevalence of small size babies over the two periods, in terms of mothers' educational attainment and wealth status, with rates barely changing, except for those with no education who experienced a reduction. We observed a higher proportion of small sized babies born in polygamous homes compared with monogamous homes in both surveys, $15.7 \%$ vs. $14.0 \%$ in $2009-2013$, and $15.5 \%$ vs. $12.4 \%$ in $2015-2018$. We observed a higher prevalence among women who did not receive tetanus injection compared with those that received tetanus injection: $19.1 \%$ vs. $13.1 \%$ and $16.6 \%$ vs. $12.7 \%$ in the corresponding periods.

In the bivariate analysis shown in Table 1, all the variables are statistically significant, except marital status and Iron intake during pregnancy in the 20092013 period. Also, in the 2015-2018 period, all the variables are statistically significant except those of the number of children ever born, source of water supply and use of mosquito net. As previously described, all the variables without indication of association with the small baby size (i.e., with the non-significant association) were subsequently excluded in the multiple logistic regression model.

Table 2 shows the results for both the univariate and multivariate logistics regression analyses. We found the sex and gender of the baby as having significant association with the risk of small size baby: Female babies had a higher chance than male babies: Adjusted Odds Ratio $(\mathrm{AOR})=1.21 ; 95 \% \mathrm{Cl}=1.14-1.29$ in the 2009-2013 period and $1.34 ; 95 \% \mathrm{Cl}=1.22-1.48$ in the 2015-2018 period. The multivariate results also indicated female babies, irrespective of their geopolitical region of residence, had a higher risk of being born as small size than male babies. Those residing in the North-East $(\mathrm{AOR}=1.56,95 \% \mathrm{Cl}=1.39$ 1.77), North-West ( $\mathrm{AOR}=1.27,95 \% \mathrm{Cl}=1.12-1.43$ ), 
Table 1: Trends in Factors Associated with Small Size Babies in Nigeria, 2009 - 2018

\begin{tabular}{|c|c|c|c|c|c|c|c|c|}
\hline \multirow{2}{*}{ Factors } & \multicolumn{4}{|c|}{2013} & \multicolumn{4}{|c|}{2018} \\
\hline & $\begin{array}{c}\text { Total births } \\
\mathbf{N}\end{array}$ & $(\%)$ & $\begin{array}{l}\% \text { of Small } \\
\text { size births }\end{array}$ & P-value & $\begin{array}{l}\text { Total } \\
\text { births } \mathrm{N}\end{array}$ & $(\%)$ & $\begin{array}{l}\% \text { of Small } \\
\text { size births }\end{array}$ & P-value \\
\hline Total & 31482 & 100 & 14.9 & & 33924 & 100 & 13.7 & \\
\hline Sex of child & & & & 0.000 & & & & 0.000 \\
\hline Male & 15965 & 50.7 & 13.4 & & 17257 & 50.9 & 12.3 & \\
\hline Female & 15517 & 49.3 & 15.8 & & 16667 & 49.1 & 14.6 & \\
\hline Region & & & & 0.000 & & & & 0.000 \\
\hline North-Central & 4614 & 14.7 & 11.0 & & 5875 & 17.3 & 12.3 & \\
\hline North-East & 6517 & 20.7 & 19.3 & & 7211 & 21.3 & 16.4 & \\
\hline North-West & 9906 & 31.5 & 16.8 & & 10305 & 30.4 & 14.9 & \\
\hline South-East & 2816 & 8.9 & 12.3 & & 3798 & 11.2 & 11.1 & \\
\hline South-South & 3747 & 11.9 & 12.4 & & 3202 & 9.4 & 11.4 & \\
\hline South-West & 3882 & 12.3 & 9.1 & & 3533 & 10.4 & 9.8 & \\
\hline Place of residence & & & & 0.000 & & & & 0.000 \\
\hline Urban & 21131 & 67.1 & 5.7 & & 11699 & 34.5 & 12.1 & \\
\hline Rural & 10351 & 32.9 & 32.7 & & 22225 & 65.5 & 14.2 & \\
\hline $\begin{array}{c}\text { Maternal age at child } \\
\text { birth }\end{array}$ & & & & 0.000 & & & & 0.003 \\
\hline$<20$ years & 4524 & 15.4 & 17.4 & & 4573 & 14.5 & 15.2 & \\
\hline 20-29years & 14917 & 50.9 & 14.2 & 3 & 16281 & 51.4 & 13.3 & \\
\hline $30-35$ & 5803 & 19.8 & 13.3 & & 6596 & 20.8 & 12.8 & \\
\hline $36+$ & 4063 & 13.9 & 15.4 & & 4207 & 13.3 & 13.5 & \\
\hline $\begin{array}{c}\text { Number of children } \\
\text { ever born }\end{array}$ & & & & 0.001 & & & & 0.054 \\
\hline$\leq 2$ & 9002 & 28.6 & 14.6 & & 9824 & 29.0 & 13.3 & \\
\hline $3-4$ & 9588 & 30.5 & 13.6 & & 10648 & 31.4 & 12.9 & \\
\hline $5+$ & 12892 & 41.0 & 15.4 & & 13452 & 39.6 & 14.0 & \\
\hline $\begin{array}{l}\text { Preceding birth } \\
\text { interval }\end{array}$ & & & & 0.026 & & & & 0.002 \\
\hline$<24$ months & 5817 & 18.5 & 17.6 & & 6706 & 24.5 & 14.6 & \\
\hline$\geq 24$ months & 19484 & 61.8 & 18.3 & & 20676 & 75.5 & 13.0 & \\
\hline $\begin{array}{c}\text { Maternal educational } \\
\text { level }\end{array}$ & & & & 0.000 & & & & 0.000 \\
\hline No education & 14762 & 46.9 & 17.8 & & 15391 & 45.4 & 15.6 & \\
\hline Primary & 6432 & 20.4 & 13.4 & & 5274 & 15.5 & 12.9 & \\
\hline Secondary & 8365 & 26.6 & 11.3 & & 10623 & 31.3 & 11.7 & \\
\hline Higher & 1923 & 6.1 & 8.1 & & 2636 & 7.8 & 9.3 & \\
\hline Wealth index & & & & 0.000 & & & & 0.000 \\
\hline Poor & 14462 & 45.9 & 18.3 & & 15809 & 46.6 & 15.3 & \\
\hline Middle & 6272 & 19.9 & 13.2 & & 7171 & 21.1 & 13.5 & \\
\hline Rich & 10748 & 34.1 & 10.5 & & 10944 & 32.3 & 10.8 & \\
\hline
\end{tabular}




\begin{tabular}{|c|c|c|c|c|c|c|c|c|}
\hline \multirow{2}{*}{ Factors } & \multicolumn{4}{|c|}{2013} & \multicolumn{4}{|c|}{2018} \\
\hline & $\begin{array}{c}\text { Total births } \\
\mathbf{N}\end{array}$ & $(\%)$ & $\begin{array}{l}\% \text { of Small } \\
\text { size births }\end{array}$ & P-value & $\begin{array}{c}\text { Total } \\
\text { births } \mathrm{N}\end{array}$ & (\%) & $\begin{array}{l}\% \text { of Small } \\
\text { size births }\end{array}$ & P-value \\
\hline Marital status & & & & 0.640 & & & & 0.046 \\
\hline Never married & 1492 & 4.7 & 14.2 & & 1698 & 5.0 & 15.0 & \\
\hline Married & 29990 & 95.3 & 14.6 & & 32226 & 95.0 & 13.4 & \\
\hline Type of marriage & & & & 0.000 & & & & 0.000 \\
\hline Monogamous & 20037 & 63.6 & 14.0 & & 22461 & 66.2 & 12.4 & \\
\hline Polygamous & 11445 & 36.4 & 15.7 & & 11463 & 33.8 & 15.5 & \\
\hline Religion & & & & 0.000 & & & & 0.000 \\
\hline Christianity & 12654 & 40.2 & 11.6 & & 13239 & 39.0 & 11.2 & \\
\hline Islam & 18354 & 58.3 & 16.6 & & 20412 & 60.2 & 14.9 & \\
\hline Others & 474 & 1.5 & 17.3 & & 273 & 0.8 & 13.5 & \\
\hline $\begin{array}{c}\text { Source of water } \\
\text { supply }\end{array}$ & & & & 0.000 & & & & 0.955 \\
\hline Unimproved & 14232 & 45.7 & 16.9 & & 15198 & 44.8 & 13.5 & \\
\hline Improved & 16905 & 54.3 & 12.6 & & 18726 & 55.2 & 13.5 & \\
\hline $\begin{array}{l}\text { Slept under } \\
\text { Mosquito net }\end{array}$ & & & & 0.039 & & & & 0.327 \\
\hline No & 24666 & 78.3 & 14.8 & & 14685 & 43.3 & 13.2 & \\
\hline Yes & 6816 & 37.6 & 13.8 & & 19239 & 56.7 & 13.7 & \\
\hline $\begin{array}{l}\text { Attended antenatal } \\
\text { care }\end{array}$ & & & & 0.000 & & & & 0.000 \\
\hline No visit & 6662 & 33.6 & 19.4 & & 5365 & 25.0 & 16.3 & \\
\hline $1-3$ & 2107 & 10.6 & 21.4 & & 3793 & 17.7 & 15.6 & \\
\hline $4+$ & 11047 & 55.7 & 10.2 & & 12307 & 57.3 & 11.8 & \\
\hline $\begin{array}{c}\text { Took Iron during } \\
\text { pregnancy }\end{array}$ & & & & 0.618 & & & & 0.000 \\
\hline No & 26704 & 94.3 & 14.1 & & 25358 & 83.0 & 13.5 & \\
\hline Yes & 1623 & 5.7 & 13.7 & & 5190 & 17.0 & 9.9 & \\
\hline $\begin{array}{l}\text { Pregnancy was } \\
\text { wanted }\end{array}$ & A & & & 0.000 & & & & 0.001 \\
\hline Wanted & 28370 & 91.1 & 14.6 & & 30355 & 89.5 & 13.3 & \\
\hline Unintended & 2236 & 7.2 & 15.7 & & 2662 & 7.8 & 14.8 & \\
\hline Unwanted & 549 & 1.8 & 14.2 & & 907 & 2.7 & 16.5 & \\
\hline $\begin{array}{l}\text { Received tetanus } \\
\text { toxoid injection }\end{array}$ & & & & 0.001 & & & & 0.000 \\
\hline No & 7811 & 24.9 & 19.1 & & 6695 & 19.7 & 16.6 & \\
\hline Yes & 23558 & 75.1 & 13.1 & & 27229 & 80.3 & 12.7 & \\
\hline
\end{tabular}

Significant at $\mathrm{P}$-value $<0.05$.

South-East $\quad(\mathrm{AOR}=1.40, \quad 95 \% \quad \mathrm{Cl}=1.19-1.64)$, and South-South (AOR=1.32, 95\% $\mathrm{Cl}=1.14-1.53)$ were significantly more likely to have a small birth size in the 2009-2013 period, compared to those in the NorthCentral region. By contrast, only those who resided in the North-East $(\mathrm{AOR}=1.26,95 \% \mathrm{Cl}=1.07-1.48)$ had a significantly higher risk compared with those in the North-Central region. Whereas the unadjusted results for both periods suggested women who resided in the rural areas had a significantly higher chance of delivering small size babies than those who lived in the urban areas, the adjusted risks were not significantly 
Table 2: Logistic Regression Analysis of Factors Associated with Small Size Babies in Nigeria, 2009-2018

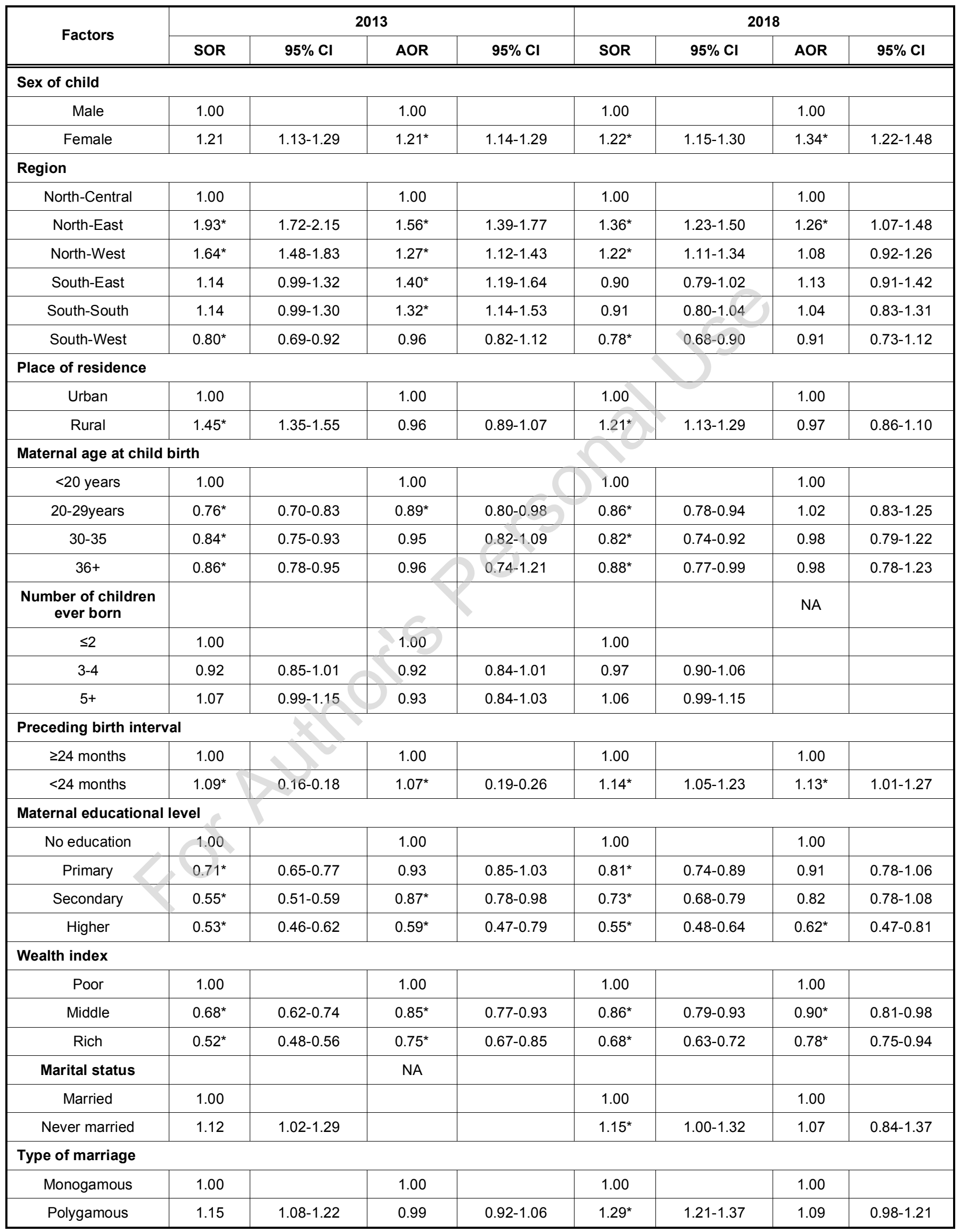


(Table 2). Continued.

\begin{tabular}{|c|c|c|c|c|c|c|c|c|}
\hline Factors & \multicolumn{4}{|c|}{2013} & \multicolumn{4}{|c|}{2018} \\
\hline \multicolumn{9}{|l|}{ Religion } \\
\hline Christianity & 1.00 & & 1.00 & & 1.00 & & 1.00 & \\
\hline Islam & $1.53^{*}$ & $1.43-1.63$ & $1.17^{*}$ & $1.05-1.31$ & $1.36^{*}$ & $1.27-1.45$ & 1.11 & $0.95-1.30$ \\
\hline Unimproved & 1.00 & & 1.00 & & 1.00 & & & \\
\hline Improved & $0.71^{*}$ & $0.66-0.75$ & $0.82^{*}$ & $0.77-0.88$ & 0.99 & $0.94-1.06$ & & \\
\hline $\begin{array}{l}\text { Slept under } \\
\text { Mosquito net }\end{array}$ & & & & & & & NA & \\
\hline \multicolumn{9}{|c|}{ Attended antenatal care } \\
\hline No visit & & & & & 1.00 & & 1.00 & \\
\hline $1-3$ & 0.87 & $0.76-1.07$ & & & 0.93 & $0.83-1.04$ & 1.16 & $0.96-1.40$ \\
\hline $4+$ & $0.65^{*}$ & $0.61-0.76$ & $0.81^{*}$ & $0.77-0.87$ & $0.68^{*}$ & $0.62-0.74$ & 1.03 & $0.86-1.24$ \\
\hline $\begin{array}{l}\text { Took Iron during } \\
\text { pregnancy }\end{array}$ & & & NA & & & & & \\
\hline No & 1.00 & & & & 1.00 & & 1.00 & \\
\hline Yes & 0.88 & $0.75-1.08$ & & 0 & $0.70^{*}$ & $0.64-0.78$ & $0.79^{*}$ & $0.68-0.92$ \\
\hline \multicolumn{9}{|c|}{ Pregnancy was wanted } \\
\hline Yes & $0.69^{*}$ & $0.65-0.76$ & $0.78^{*}$ & $0.77-0.98$ & $0.72^{*}$ & $0.67-0.78$ & $0.80^{*}$ & $0.68-0.94$ \\
\hline
\end{tabular}

*Significant at $\mathrm{P}$-value<0.05. NA Not available. SOR=Specific Odd Ratio. AOR=Adjusted Odd Ratio.

different in either period. After adjusting for the effects of other factors, we found that mothers aged 20-29 years at child birth were considerably less likely to give birth to small size babies than mothers aged $<20$ years, but only in the 2009-2013 period (AOR $=0.89,95 \%$ $\mathrm{Cl}=0.80-0.98)$. The adjusted results also suggested the risk of having small size babies was significantly higher for children delivered at preceding birth interval of fewer than 24 months compared with those delivered at a birth interval of 24 months or more in both the 20092013 (AOR=1.07, 95\% Cl $=0.19-0.26)$ and 2015-2018 (AOR=1.13, 95\% Cl $=1.01-1.27)$ periods.

In terms of mother's educational level, we found evidence of a reduction in the risk of delivering small size babies with increased educational attainment in the 2009-2013 period: the risks were less for mothers with secondary and higher education (AOR $=0.87,95 \%$ $\mathrm{Cl}=0.78-0.98)$ and $(\mathrm{AOR}=0.59,95 \% \mathrm{Cl}=0.47-0.79)$ respectively compared to those with no formal education. However, the risk was significantly less only for mothers with higher educational levels in the 20152018 period $(A O R=0.62,95 \% \mathrm{Cl}=0.47-0.81)$. We also found that the better the household wealth index, the lower the risk of delivering small size babies in both periods. Mothers from middle and rich status households were significantly less likely to have small size babies at birth $(\mathrm{AOR}=0.85,95 \% \mathrm{Cl}=0.77-0.93)$ and $(\mathrm{AOR}=0.75,95 \% \mathrm{Cl}=0.67-0.85)$ respectively compared with women from a poor household in the 2009-2013 period. Similar results were found for the 2015-2018 period: mothers from middle and rich status households: $\mathrm{AOR}=0.90,95 \% \mathrm{Cl}=0.81-0.98$ and $\mathrm{AOR}$ 
$=0.78,95 \% \mathrm{Cl}=0.75-0.94$ respectively. The adjusted results also showed that the risk of low size birth did not vary significantly between women in polygamous and monogamous relationships. However, Islamic women were significantly more likely to have small size babies at birth than Christian mothers (AOR $=1.17$, $95 \% \mathrm{Cl}=1.05-1.13$ ) in 2009-2013, although the risk was not significantly different in 2015-2018. Furthermore, women who had access to an improved water supply source were significantly less likely to give birth to small sized babes compared to women in households with no access to improved water supply (AOR $=0.82$, $95 \% \mathrm{Cl}=0.77-0.88)$, but only in the $2009-2013$ period.

For health-seeking behavior-related factors, we found that the frequency of antenatal care attendance during pregnancy has a significant associated with the risk of small size baby, but only in the 2009-2013 period. Women who attended a minimum of four ANC visits during the 2009-2013 period were significantly less likely to have small size babies at birth (AOR $=0.81,95 \% \mathrm{Cl}=0.77-0.87$ ) compared with women who did not attend antenatal care during the pregnancy period. We found no evidence of an association between the use of mosquito nets and the risk of small sized babies at birth. Hence, that variable was dropped. Information on Iron intake during pregnancy was only available in the 2018 survey. It was found to be significantly related to the risk of delivering small size babies: women who took iron pills during pregnancy were found to have a lower risk compared to those who did not receive iron pills. The results also indicated higher risk for unintended and unwanted pregnancies compared to wanted pregnancies, in both survey periods: $A O R=1.21(95 \% \mathrm{Cl}=1.04-1.50)$ and $\mathrm{AOR}=1.23(95 \% \mathrm{Cl}=1.03-1.48)$ for unintended pregnancies and $\mathrm{AOR}=1.32(95 \% \mathrm{Cl}=1.15-1.86)$ and $\mathrm{AOR}=1.42(95 \% \quad \mathrm{Cl}=1.12-1.80)$ for unwanted pregnancies, in the periods 2009-2013 and 2015-2018 respectively. Receiving tetanus toxoid injection was found to be significantly associated with a lower risk of giving birth to a small size baby compared to those who did not receive one: $\mathrm{AOR}=0.78(95 \% \mathrm{Cl}=0.77-0.98)$ and $\mathrm{AOR}=0.80(95 \% \mathrm{Cl}=0.68-0.94)$ for periods 2009 2013 and 2015-2018 respectively.

\section{DISCUSSION}

We used the mother's perception of the small size of the baby as a proxy for our definition of low birth weight in this study. Our results indicated a slight but declining trend in the prevalence of small size babies in Nigeria from $14.9 \%$ as of 2013 to $13.7 \%$ in 2018 .
These results are similar to those described in the Multiple Indicator Cluster Survey report on low birth weight infants [14]. When considered over the two NDHS survey periods, 2009-2018, we can see that the prevalence in Nigeria was lower than those for Bangladesh (17.2\%) [16] and Ethiopia (29.1\%) [17], but slightly higher than the prevalence in Pakistan (10.6\%) [18].

We identified certain demographic, socio-economic, and healthcare utilization factors on which we found evidence of association with the risk of low birth weight in Nigeria. These are the sex of the child, geopolitical region, maternal age, maternal education, wealth index, religion, source of water supply, number of antenatal clinics (ANC) visits, iron intake during pregnancy, desirousness of pregnancy and intake of tetanus toxoid injection. Female children are more likely to be of the small size at birth; this finding was consistent with two previous studies, one in Nigeria [19] and another in Bangladesh [16]. Under-utilization of health care service and low nutritional intake during pregnancy have been reported elsewhere as possible responsible [20]. The mother's age at child birth was also identified to have a statistically significant association with the risk. Women aged 20-29 years were less likely to deliver small size babies than the other age groups, which is consistent with previous studies in Nigeria [20] and abroad [17].

We also found that the mother's educational level and household wealth index were significantly associated with small sized babies at birth. Mothers who have higher educational attainment and better household wealth status have lower risk- results, which are consistent with the findings in some other studies $[16-17,19,20]$. In particular, women with secondary or higher education levels are significantly less likely to give birth to small sized babies. One explanation is that better educated and privileged women are likely to have increased knowledge and awareness of healthy living and are more likely to be able to afford better health care services [16]. Other findings include higher risk among Islamic women when compared with Christian women which could be attributed to the high proportion of teenage pregnancy and motherhood in the northern part of Nigeria, where over half of the population are Muslims [21]. Antenatal care (ANC) attendance in reducing the risk of low birth weight, which has previously been reported as a part of the general risk of adverse pregnancy outcomes and the importance of frequent ANC attendance for women's health during pregnancy $[16,22,23]$. The reasons 
presented including ANC visits are enhancing the dietary practices of mothers, promoting proper monitoring of both mothers and fetuses during the period of pregnancy, and enabling health care providers to discover any clinical and obstetric complications to initiate early interventions and treatment, which would improve the outcomes $[16,23]$. As previously reported by other studies, women with access to improved water supply were found to have a lower risk of small size babies than those with poor or unimproved sources $[24,25]$. One explanation is that poor or unimproved water sources are often contaminated with biological and chemical hazards such as macro-organism, benzene, and trichloroethylene (TCE), which can cause defects and diseases to mothers and unborn children [26, 27].

Our study also added to the growing evidence of a significant relationship between unintended and unwanted pregnancies and the risk of small size babies $[16,28,29]$. Some have suggested women who have unintended and unwanted pregnancies may be reluctant or less likely to receive the right antenatal care and are more likely to indulge in smoking or alcohol consumption than those with wanted pregnancies [28, 29]. We found an association between receiving iron pills during pregnancy and lower risk of small size babies at birth- a finding previously reported by other studies in Nigeria [19] and Ethiopia [30]. The importance of iron intake during pregnancy in reducing the LBW risk has also been emphasized [31, 32]. Another finding is the association between tetanus toxoid injection and lower risk of small sized babies, which is consistent with the finding from a study in Rural North India that reported a reduced risk of neonatal deaths with at least one dose of tetanus toxoid [33]. Of course, other studies have already reported a small size at birth as a risk factor for childhood mortality [5-7, 34].

\section{CONCLUSION}

This study presents the national prevalence of reported small size babies at birth, which we considered as a proxy for low birth weight, using data from 2013 NDHS and 2018 NDHS in Nigeria. Our results indicate a slight but declining trend in the prevalence of low birth weight in Nigeria throughout the two surveys, namely between 2009-2018. However, despite the slight decline, prevalence rates are still very high in Nigeria. We found evidence of an association between the risk of low birth weight and the sex of the child, geopolitical region, maternal age at the birth of the child, maternal education, wealth index, religion, source of water supply, number of antenatal visits, iron intake during pregnancy, desirousness of pregnancy and intake of tetanus toxoid injection. In light of the adverse effects of low birth weight on child growth, development and survival, we recommend the implementation and prioritization of active, and resourceful public health interventions, if Nigeria is to sustain the little progress achieved so far in reducing the current high rate.

\section{ETHICAL ISSUES}

Ethical approval was not needed since NDHS does not require direct or primary source data collection. However, permission to use the data was obtained from ORC Macro International via the DHS website.

\section{CONFLICTS OF INTEREST}

None to declare.

\section{FUNDING SOURCE}

None to declare.

\section{REFERENCES}

[1] Lawn JE, Cousens S, Zupan J. 4 million neonatal deaths: When? Where? Why? Lancet 2005; 365: 891-990. https://doi.org/10.1016/S0140-6736(05)71048-5

[2] Uthman OA. Effect of low birth weight on infant mortality: analysis using Weibull Hazard Model. Int J Epidemiol 2008; 6: 8. https://doi.org/10.5580/fca

[3] Daynia EB, Tobias FC, Peter AC. Determinants of survival in very low birth weight neonates in a public sector hospital in Johannesburg. BMC Pediatr 2010; 10: 1030. https://doi.org/10.1186/1471-2431-10-30

[4] World Health Organization (WHO). Guidelines on optima feeding of low birth-weight infants in low- and middle-income countries 2011; 5-31? (accessed April 12, 2020).

[5] Adebowale SA, Morakinyo OM, Ana GR. Housing materials as predictors of under-five mortality in Nigeria: evidence from 2013 demographic and health survey. BMC Pediatr 2017; 17: 30. https://doi.org/10.1186/s12887-016-0742-3

[6] Wegbom Al, Essi ID, Kiri VA. Survival Analysis of Under-five Mortality and Its Associated Determinants in Nigeria: Evidence from Survey Data. Int J of Stat and Appl 2019; 9(2): 59-66

[7] Wegbom Al, Kiri VA, Essi, ID. Comparison between SemiParametric Cox and Parametric Survival Models in Estimating the Determinants of Under-Five Mortality in Nigeria: Application in Nigerian Demographic and Health Survey. Afr J of Math and Stat Stud 2019; 2(2): 1-12.

[8] Pojda D, Kelly L. Low birthweight-nutrition policy discussion paper no.18. UNACC Sub-Committee on Nutrition 2000 (accessed April 12, 2020)

[9] Islam MM. The Effects of Low Birth Weight on School Performance and Behavioral Outcomes of Elementary 
School Children in Oman, Oman. Medical J 2015; 30: 241251.

https://doi.org/10.5001/omj.2015.50

[10] United Nations Children's Fund (UNICEF), World Health Organization (WHO), UNICEF-WHO (2019) Low birthweight estimates: Levels and trends 2000-2015. Geneva: World Health Organization; CC BY-NC-SA 3.0 IGO. (accessed April 12, 2019).

[11] United Nations Children's Fund (UNICEF) Country, Regional and Global Health Facts; monitoring the situation of Children and Women, World Health Statistics 2009. (accessed April 12, 2019).

[12] World Health Organization (WHO). Global nutrition targets 2025: low birth-weight policy brief (WHO/NMH/NHD/14.5). Geneva: World Health Organization, 2014. (accessed December 12, 2019).

[13] United Nations Children's Fund (UNICEF) Country, Regional and Global Health Facts; monitoring the situation of Children and Women, World Health Statistics 2016 (accessed April 12, 2019).

[14] National Bureau of Statistics (NBS) and the United Nations Children's Fund (UNICEF). Multiple Indicator Cluster Survey 2016-17, Survey Findings Report. Abuja, Nigeria, 2017. http://www.nigerianstat.gov.ng/pdfuploads/MICS-\%20201617\%20National.pdf (accessed April 12, 2020).

[15] Kleinbaum D, Mitchel K. Logistic Regression: A Self-Learning Text.3rd ed. Springer Science + Business Media, Inc., 2010; pp. 1-27.

[16] Islam MM, Khan MHR. Incidence of and Risk Factors for Small Size Babies in Bangladesh. Int J Community Fam Med 2016; 1: 123.

https://doi.org/10.15344/2456-3498/2016/123

[17] Taddese A, Melaku U. Prevalence and Predictors of "Small Size" Babies in Ethiopia: In-depth Analysis of the Ethiopian Demographic and Health Survey, 2011. Ethiopia J of Health Sci 2016; 26(3): 243-250.

https://doi.org/10.4314/ejhs.v26i3.7

[18] Khan A, Deeba FN, Jaleel R. Frequency, and risk factors of low birth weight in term pregnancy. Pakistan $\mathrm{J}$ of Med Sci 2016; 32(1): 138-142.

https://doi.org/10.12669/pjms.321.8120

[19] Isiugo-Abnihe UC, Oke OA. Maternal and environmental factors influencing infant birth weight in Ibadan, Nigeria. Afr Popul Stud 2011; 25(2): 250-266. https://doi.org/10.11564/25-2-230

[20] Maznah D, NazarAzahar OM, Norlaili A. Risk factors for low birth weight in Nigeria: evidence from the 2013 Nigeria Demographic and Health Survey. Global Health Action 2016;

[21] National Population Commission (NPC) [Nigeria] and ICF. Nigeria Demographic and Health Survey, 2018. Abuja, Nigeria, and Rockville, Maryland, Maryland, USA: NPC and ICF. 2019. (accessed April 12, 2020)

[22] Hueston WJ, Gilbert, GE, Davis L Sturgill V. Delayed prenatal care and the risk of low birth weight delivery. $\mathrm{J}$ of Comm Health 2003; 28: 199-208. https://doi.org/10.1023/A:1022908307844
[23] White DE, Fraser-Lee NJ, Tough S, Newburn-Cook CV. The content of prenatal care and its relationship to preterm birth in Alberta, Canada. Health Care for Women Int 2006; 27: 777-792.

https://doi.org/10.1080/07399330600880335

[24] Currie J, Joshua GZ, Katherine M, Matthew N, Wolfram S. Something in the water: contaminated drinking water and infant health. Canadian J Economics 2013; 46(3): 791-810. https://doi.org/10.1111/caje.12039

[25] Ghosh S. Water access and sanitation shape birth outcomes and earning potential. https://india.mongabay.com/2018/11/ water-access-and-sanitation-shapes-birth-outcomes-andearning-potential/ (accessed April 12, 2019).

[26] Ruckart PZ, Bove FJ, Maslia M. Evaluation of contaminated drinking water and preterm birth, small for gestational age, and birth weight at Marine Corps Base Camp Lejeune, North Carolina: a cross-sectional study. BMC Environ Health 2014; 13: 99.

https://doi.org/10.1186/1476-069X-13-99

[27] Aschengrau A, Gallagher LG, Winter M, Butler L, Fabian MP Vieira VM. Modeled exposure to tetrachloroethylene contaminated drinking water and the occurrence of birth defects: a case-control study from Massachusetts and Rhode Island. BMC Environ Health 2018; $17: 75$. https://doi.org/10.1186/s12940-018-0419-5

[28] Eggleston E, Tsui AO, Kotelchuck M. Unintended Pregnancy and Low Birthweight in Ecuador. Amer J Public Health 2001; 91: 808-816.

https://doi.org/10.2105/AJPH.91.5.808

[29] Shah PS, Balkhair T, Ohlsson A, Beyene J, Scott F, Frick C. Intention to Become Pregnant and Low Birth Weight and Preterm Birth: A Systematic Review. Mater and Child Health J 2011; 15: 205-216. https://doi.org/10.1007/s10995-009-0546-2

[30] Yisak G, AberaHaftu SW, Haftom G. The Prevalence and Risk Factors for Low Birth Weight among Term Newborns in Adwa General Hospital, Northern Ethiopia. Obstetrics and Gynecology International 2017. (accessed April 12, 2020). https://doi.org/10.1155/2017/2149156

[31] Cogswell ME, Parvanta I, Ickes L, Yip R, Brittenham GM Iron supplementation during pregnancy, anemia, and birth weight: a randomized controlled trial. The American Journal of Clinical Nutrition 2003; 78(4): 773-781. https://doi.org/10.1093/ajcn/78.4.773

[32] Haider BA, Olofin I, Wang M, Spiegelman D, Ezzati M, Fawzi WW. Anaemia, prenatal iron use, and risk of adverse pregnancy outcomes: systematic review and meta-analysis. 2013. (accessed April 12, 2019)

[33] Singh A, Pallikadavath S, Ogollah R, Stone W. Maternal Tetanus Toxoid Vaccination and Neonatal Mortality in Rural North India. PloS One 2012; 7: 11.

https://doi.org/10.1371/journal.pone.0048891

[34] Wegbom Al, Essi ID, Kiri VA. Estimation of the Family and Community Unobserved Heterogeneity Effects on the Risk of Under-Five Mortality in Nigeria using the Frailty Model. International Journal of Child Health \& Nutrition 2020; 9(1): 17-25.

https://doi.org/10.6000/1929-4247.2020.09.01.3 